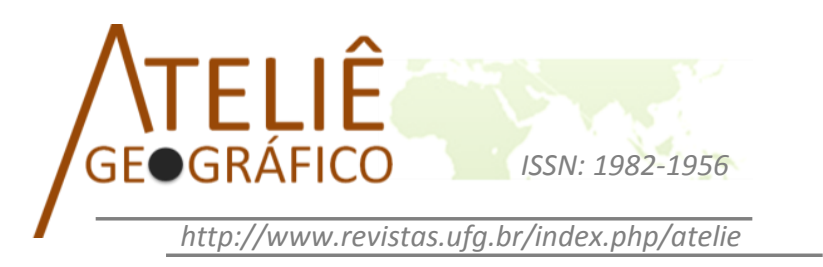

\title{
Território e conflitos ambientais do turismo de segunda residência na APA litoral Sul (SE)
}

\author{
Territorio y conflictos ambientales del turismo \\ de segunda residencia en el APA litoral Sur (SE) \\ Territory and conflict environmental the tourism of \\ second home in epa south coast (SE) \\ Priscila Pereira Santos \\ Instituto Federal de Educação, Ciência e Tecnologia de Sergipe \\ p.p.s2902@gmail.com \\ José Wellington Carvalho Vilar \\ Instituto Federal de Educação, Ciência e Tecnologia de Sergipe \\ Universidade Federal de Sergipe \\ wvilar@yahoo.com.br
}

\begin{abstract}
Resumo
Em Sergipe, a Unidade de Conservação de Uso Sustentável APA (Área de Proteção Ambiental) Litoral Sul foi criada com intuito de garantir a exploração do meio de forma a manter a perenidade dos recursos ambientais renováveis. Porém, observa-se nessa unidade de conservação o desdobramento de diversificados conflitos socioambientais advindos do uso inadequado $\mathrm{e}$ desrespeitoso da natureza, além da ocupação irregular, principalmente por meio de casas de veraneio e do turismo. A presente pesquisa tem como objetivo principal analisar os conflitos ambientais e os impactos territoriais relacionados ao turismo de segunda residência na APA Litoral Sul de Sergipe. Para realizar a presente pesquisa foram executados os seguintes procedimentos metodológicos: levantamento e leitura do material bibliográfico; levantamento de dados estatísticos, pesquisa de campo, entrevistas e análise e interpretação dos resultados. Conclui-se que a ampliação dos eixos indutores de ocupação e o crescimento do turismo de segunda residência na APA Litoral Sul são
\end{abstract}


acompanhados do aumento de problemas e conflitos ambientais, ficando evidente a necessidade de um gerenciamento integrado da zona costeira sergipana.

Palavras-Chave: Território; Conflitos Ambientais; Unidade de Conservação de Uso Sustentável; Turismo de Segunda Residência.

\title{
Resumen
}

En Sergipe, la Unidad de Conservación de Uso Sostenible APA (Área de Protección Ambiental) de la Costa Sur ha sido diseñada para garantizar la explotación del medio ambiente con el fin de mantener la sostenibilidad de los recursos renovables del medio ambiente. Sin embargo, se observa en que unidad de conservación lo despliegue de los diversos conflictos ambientales derivados del uso inadecuado de la naturaleza y la falta de respeto, además de la ocupación ilegal, principalmente a través de casas de vacaciones y el turismo. Esta investigación tiene como objetivo analizar los conflictos ambientales y los impactos territoriales relacionados con el turismo de segunda residencia en el APA costa sur de Sergipe. Para llevar a cabo esta investigación fueron ejecutados los siguientes procedimientos metodológicos: revisión de la literatura, sistematización de datos estadísticos, investigaciones de campo, entrevistas y análisis e interpretación de resultados. Llegamos a la conclusión de que la expansión de los ejes de la ocupación y el crecimiento que induce el turismo de segunda residencia en el APA Costa Sur de Sergipe están acompañados por el aumento de los problemas y conflictos ambientales, lo que hace evidente la necesidad de un enfoque integrado de la zona costera sergipana.

Palabras clave: Territorio; Conflicto Ambiental; Unidad de Conservación de Uso Sostenible; Turismo de segunda residencia.

\begin{abstract}
In Sergipe, the South Coast Unit for Sustainable Use Conservation, EPA (Environmental Protection Area) has been crafted to ensure the exploitation of the environment in order to maintain the sustainability of renewable environmental resources. However, it is noted that the Conservation Unit deployment of diverse environmental conflicts arising from the use of inappropriate and disrespectful nature, besides the illegal occupation, primarily through vacation home and tourism. This research aims at analyzing the social and environmental conflicts and territorial impacts related to tourism as a second home on the South Coast EPA of Sergipe. To accomplish this research, it was used the following methodology: literature review; statistical data, field research, interviews and analysis and interpretation of results. It was observed that the expansion of the axes of occupation and the inducing growth of tourism of second residence on the South Coast EPA have been accompanied by the increase of environmental problems and conflicts which makes evident the need for an integrated management of the Sergipe South Coast.
\end{abstract}

Keywords: Territory; Environmental Conflict; Conservation Unit of Sustainable Use (EPA); Tourism of Second Residence.

\section{Introdução}

Para sobreviver e desenvolver suas atividades, homens e mulheres usam, delimitam, definem, se apropriam e dão significado a uma porção do espaço que pode ser denominado de território e ser considerado como um 
recorte geográfico. Os grupos sociais e, ou, os indivíduos convivem a partir das relações de poder que um grupo exerce sobre o outro na tentativa de dominar o território (SOUZA, 2009).

Ao estabelecer vínculos com o território os indivíduos passam a se identificar com o patrimônio material e imaterial e criam territorialidades ou identidades espaciais. Para Saquet (2009), a territorialidade nos indivíduos ou grupos sociais é influenciada por vários aspectos do próprio território, como por exemplo, a cultura, a política, a economia e o meio ambiente. As diversas territorialidades existentes no mesmo território são construídas por pessoas que concebem os recursos territoriais de maneiras distintas.

No Brasil foram delimitados territórios que apresentam elevada fragilidade ambiental com o objetivo de proteção integral da natureza e de compatibilização entre a conservação e o uso sustentável dos recursos. Para limitar o uso dos recursos ambientais e assegurar o controle territorial estratégico, foi implantado o Sistema Nacional de Unidade de Conservação (SNUC) que é responsável pela regulação de espaços territoriais legalmente protegidos, as unidades de conservação (UC).

Tendo em vista a peculiaridade e fragilidade dos ecossistemas litorâneos em Sergipe, foi criada a Unidade de Conservação de Uso Sustentável APA (Área de Proteção Ambiental) Litoral Sul para manter a perenidade dos recursos ambientais e tentar disciplinar o uso e ocupação do solo. Porém, observa-se nessa unidade de conservação o desdobramento de conflitos socioambientais advindos do uso inadequado da natureza, além da ocupação irregular, principalmente por meio de casas de veraneio e do turismo.

A proliferação desordenada das segundas residências ou alojamentos turísticos particulares na APA Litoral Sul provoca conflitos socioambientais entre os moradores locais, os turistas e as autoridades oficiais, uma vez que esses turistas de final de semana causam impactos ao meio ambiente e as consequências são sofridas pelos moradores permanentes, em que pese à ação do Estado como regulador e como agente de ordenamento territorial. Devido à relação ambígua entre esses atores sociais, a presente pesquisa tem como objetivo principal analisar os conflitos ambientais e os impactos territoriais relacionados ao turismo de segunda residência na APA Litoral Sul de Sergipe em termos de ocupação territorial, apropriação dos recursos naturais, e socioambientais.

Sob esta perspectiva, algumas questões de pesquisa norteiam a presente análise. Inicialmente, questiona-se se a construção de infraestrutura territorial provocou o aumento das segundas residências na APA Litoral Sul de Sergipe ou o crescimento das segundas residências demandou à inserção de novas materialidades geográficas? Em seguida e no que se refere aos conflitos, 
indaga-se até que ponto o turismo de segunda residência influencia conflitos entre os veranistas e os moradores permanentes APA Litoral Sul de Sergipe? E por fim, quais as implicações territoriais e ambientais do turismo de segunda residência na APA Litoral Sul de Sergipe?

Para o presente estudo, o foco da análise está centrado nos conflitos de natureza ambiental que na concepção de Little (2001, p. 107) é definido como "disputas entre grupos sociais derivadas dos distintos tipos de relação que eles mantem com seu meio natural”. Já para Acselrad (2004, p. 26),

\begin{abstract}
os conflitos de natureza ambiental envolvem grupos sociais com modos diferenciados de apropriação, uso e significação do território, tendo origem quando pelo menos um dos grupos tem a continuidade das formas sociais de apropriação do meio que desenvolvem ameaçada por impactos indesejáveis - transmitidos pelo solo, água, ar ou sistemas vivos - decorrentes do exercício das práticas de outros grupos.
\end{abstract}

O litoral é um território de transição entre o oceano e o continente que se configura como um conjunto de elementos naturais e de múltiplas atividades humanas, com territorialidades e conflitos ambientais singulares em termos de acesso, uso, apropriação e significado de recursos rurais, urbanos e de unidades territoriais legalmente protegidas. A base geográfica de uma dada existência social no litoral se manifesta na interação entre homem e espaço.

No âmbito dos assentamentos humanos costeiros e litorâneos, podemse evidenciar a crescente intensidade e densificação de ocupação por meio de uma série de atividades promotoras de conflitos e impactos: urbanização, industrialização, instalação de complexos portuários, extrativismo agrícola de comunidades tradicionais, pesca, exploração de petróleo, turismo, atividades de lazer e de ócio e a segunda residência que tem crescido bastante nos últimos anos.

Como toda atividade humana é inerente ao conflito e aos impactos, a compreensão geográfica do litoral envolve a discussão das formas de controle social do território e das interações entre homem e a base material da sua existência, o espaço, na perspectiva de entender a ocupação desordenada, a degradação ambiental e as iniciativas de ordenamento territorial.

A estreita relação entre o turismo e a segunda residência no litoral, evidenciado pelo turismo de segunda residência, será aqui analisada como um elemento que se destaca entre as atividades promotoras de conflitos por impulsionar a (re) organização do território entrelaçada aos impactos. Em síntese, conflitos ambientais, impactos territoriais, territorialidades e ocupação 
desordenada do espaço estão na base da compreensão da ordem e da desordem do litoral na atualidade.

\section{Território e conflitos socioambientais no litoral}

A atualidade da categoria território é indiscutível não só na ciência geográfica, mas nas ciências sociais como um todo e também em outros campos do conhecimento científico, a exemplo da biologia e da engenharia agronômica. De acordo com Santos (2002, p. 9) "nada considerado essencial hoje se faz no mundo que não seja a partir do conhecimento do que é Território".

O território é uma das categorias de análise geográfica que se destaca por apresentar uma diversidade de compreensões e significados, que variam conforme a visão dos paradigmas do pensamento geográfico, o escopo do estudioso e o objeto de pesquisa. O termo território advém do latim terra e torium, como indica Corrêa (1996), que significa terra pertencente a alguém. Para Milton Santos:

O território é o chão e mais a população, isto é, uma identidade, o fato e o sentimento de pertencer àquilo que nos pertence. $\mathrm{O}$ território é à base do trabalho, da residência, das trocas materiais e espirituais e da vida, sobre os quais ele influi. Quando se fala em território deve-se, pois, de logo, entender que se está falando em território usado, utilizado por uma dada população (2002, p. 96).

O território pode ser interpretado como um produto das relações sociais, constituído de elementos históricos, econômicos, políticos e culturais. Mas, em primeiro lugar, conforme Souza (2009) e Haesbaert (2004), a definição de território deriva do exercício das relações de poder e a projeção dessas relações no espaço. Para Haesbaert (2004), o território pode ser entendido a partir da complexa imbricação de múltiplas relações de poder, desde aquele poder mais estritamente material das relações econômicas e políticas ao poder simbólico das relações de ordem cultural. Segundo Souza (2009), o território é a expressão espacial do poder exercido socialmente.

O território, quando compreendido como espaço de governança, é múltiplo e pluriescalar correspondente na maioria das vezes à nação e ao país, e às regionalizações administrativas em termos de estados e outros recortes regionais e locais. Para além do espaço de governança, formam-se outros territórios também muldimensionais e multiescalares que respondem pelo âmbito do poder público ou do estritamente privado, a exemplo da casa, do bairro, de empresas e das segundas residências que aqui nos interessa mais de 
perto. Como se vê, a abrangência e a complexidade da categoria território são amplas e convidam a reflexões interdisciplinares e abertas.

Segundo Haesbaert (2004), o território contém três vertentes básicas: jurídico-política, no qual é visto como um espaço delimitado e controlado sobre o qual se exerce um determinado poder político, especialmente de caráter administrativo, governamental e que atua no âmbito público da esfera de atuação do Estado; cultural, o território é o produto da apropriação feita individual ou coletivamente através do imaginário e/ou identidade social sobre o espaço geográfico; econômica, o território é visto como produto espacial do embate entre classes sociais e da relação capital-trabalho.

Nesse sentido, o território significa o controle, a delimitação, o acesso, a apropriação econômica e identitária, a significação, o uso e a ocupação de um determinado espaço. Para Raffestin (2009), o espaço é como se fosse uma matéria-prima, anterior ao território, ou seja, a partir dele e de ações de apropriação, conduzidas por atores ocorre a territorialização do espaço, ou seja, o espaço é tornado produto.

Na visão esclarecida de Marcelo Souza (2009), o espaço social possui inúmeras facetas, e o território é uma delas. Na concepção de Souza (1995, p. 99), a territorialidade corresponde a "certo tipo de interação entre homem e espaço, a qual é sempre uma interação entre seres humanos mediatizada pelo espaço". A territorialidade é um fenômeno social ligado principalmente ao lugar e a região e significa, conforme aponta Saquet (2009, p. 90), a tentativa de um grupo ou de um indivíduo de obter o controle das pessoas e das relações sociais no território; "a territorialidade corresponde ao poder exercido e extrapola as relações políticas envolvendo as relações econômicas e culturais, indivíduos e grupos, redes e lugares de controle, mesmo que seja temporário, do e no espaço geográfico com suas edificações e relações".

Nessa perspectiva, é conveniente destacar que as territorialidades dão ao lugar identidade, manifestando-se na cultura e no comportamento dos indivíduos, e tem influência direta do processo histórico e geográfico de construção do lugar, da região e do espaço. No caso da região, embora também apresente uma conotação instrumental, intervencionista e normativa, o debate regional atual revigora o papel da identidade e da descentralização e desconcentração do poder político econômico. Como adverte Haesbaert (2010, p. 117) de maneira lúcida "qualquer análise regional que se pretenda consistente [...] deve levar em conta tanto o campo da produção material quanto o das representações e símbolos." Por último, vale ressaltar, ainda com base em Haesbaert (2010, p 166) que "sem espaço não há território" e, deve-se acrescentar, sem espaço tampouco existe territorialidade. 
Em um mesmo território podem existir várias territorialidades e nascem assim, interesses divergentes no uso dos recursos ambientais. Nesse sentido, cada grupo social ou indivíduo causa impacto de ordem social, econômica, política, ideológica, cultural e ambiental de acordo com a sua visão e interesses sobre o território o que ocasiona conflitos entre os atores sociais que usam a mesma base material ou entre atores de territórios diferentes. Vieira (2010, p. 78) ressalta que "o território é detentor de significados diferenciados capazes de promoverem a geração de disputas e conflitos pelos seus recursos".

Na visão de Nascimento (2001, p. 94) "os conflitos são meios pelos quais os atores sociais dirimem suas divergências, interesses antagônicos ou pontos de vista conflitantes, possibilitando que a sociedade alcance uma certa unidade". Para o referido autor, os conflitos são formados por um conjunto de elementos que os caracterizam, dentre os quais se destacam: natureza (econômica, política, social, ambiental, cultural, doméstica, geracional, de gênero, entre tantas outras); atores sociais diversos com interesses distintos; campo material do conflito; objeto em disputa que pode ser material ou simbólico, divisível ou indivisível, laico ou profano, real ou irreal; lógica ou dinâmica de desenvolvimento; mediadores; e tipologia variada, segundo o critério que se utilize.

\section{O Turismo de Segunda Residência no Litoral}

O homem urbano tem um cotidiano marcado por estresse ocasionado, dentre outros motivos, pela industrialização e pela urbanização da chamada sociedade do automóvel. Nesse sentido, torna-se perceptível a necessidade desse indivíduo ter contato com ambientes e paisagens diferentes para renovar as energias.
A possibilidade de sair, de viajar, reveste-se com toda a evidência, de uma grande importância. Afinal, o cotidiano só é suportável se podemos escapar do mesmo, sem o que o ser humano perde o equilíbrio e adoece. O lazer, sobretudo as viagens, deve atrair raios de cor na tela cinzenta da existência. Eles devem reconstituir - reciclar - o homem, curar e sustentar o corpo e a alma, proporcionar uma fonte de forças vitais e trazer um sentido à vida (KRIPPENDORF, 2007, p. 34).

Nessa perspectiva, o turismo se destaca como uma forma de lazer capaz de produzir nas pessoas sensação de bem-estar e satisfação (BACAL, 2003) e tem nos espaços de praia um dos lugares mais requisitados pelos homens contemporâneos, configurando o que se define na literatura sobre ocupação territorial como o modelo turístico de sol e praia. Dantas et. al. 
(2010) ressalta que a valorização da paisagem e as singularidades do litoral tornam os espaços à beira-mar objeto de desejo dos indivíduos para realizar atividade de turismo, lazer, e ócio.

Segundo a Organização Mundial de Turismo (OMT, 1998, p. 44), “o turismo compreende as atividades que realizam as pessoas durante suas viagens e permanências em lugares distintos ao seu entorno habitual, por um período de tempo consecutivo inferior a um ano com fins de ócio, por negócios e outros". Os turistas podem utilizar os diversificados meios de hospedagem existentes no destino, e dentre as ofertas destacam-se as segundas residências.

Ao falar em turismo como uma utilização temporária de uma área diferente da sua residência habitual, que visa desenvolver um conjunto de atividades ociosas, existe dois tipos principais de relação com o espaço. Em primeiro lugar, e num sentido mais estrito, não dá um turismo que não estabelece vínculo territorial permanente, com o espaço de lazer que se dirige. Em segundo lugar, encontramos um turismo permanente com o uso do mesmo espaço, que dá origem a alguma forma de vínculo territorial e psicossociológico, gerando-se o que se tem denominado como residência secundária (SANCHÉZ, 1991, p. 160). (Grifo nosso).

As expressões segunda residência, residência secundária e residência de férias ou de ócio são utilizadas para designar basicamente a mesma ideia. Mas diversas outras denominações são utilizadas na bibliografia nacional e internacional para denominar esse fenômeno. Em língua portuguesa é grande a riqueza de expressões: domicílio de uso ocasional, residência turística, residência secundária, segunda residência, casa de veraneio, de praia e vilegiatura; em francês, residence secondaire, residence touristique; em inglês, second home, vacation home; em espanhol, segunda casa, casas vacacionales; entre outras expressões.

Segundo Tulik (2001), a segunda residência é um alojamento turístico particular, utilizado temporariamente, nos momentos de lazer, por pessoas que tem seu domicílio permanente em outro lugar e quando localizadas no litoral são comumente chamadas de casas de praia ou de veraneio e de vilegiatura marítima. No mesmo diapasão, o geógrafo espanhol López Colás (2003, p. 28) define a segunda residência como "casa destinada ao ócio, localizada em um espaço recreacional e ocupada unicamente uma parte do ano". Já a OMT (2008) conceitua a segunda residência como a propriedade residencial para fins de veraneio e turismo, não sendo, portanto, a residência principal do titular. Nesse espaço, serviços relacionados com turismo são oferecidos.

De acordo com Mazón e Aledo (2005, p. 18-19), o turismo residencial pode ser definido como uma "atividade econômica que se dedica à 
urbanização, construção e venda de imóveis turísticos-residenciais que não compõem o setor hoteleiro tradicional, cujos usuários os utilizam como alojamento para veranear ou residir, (...), fora de seus lugares de residência habitual". Estas residências podem ser próprias, alugadas ou cedidas e se constituem o meio de hospedagem do turista de segunda residência. Vale ressaltar que, além dos diferentes benefícios que trazem aos turistas, comprar uma segunda residência hoje é uma opção de investimento. Valores culturais e ganhos econômicos ajudam a explicar a opção pela segunda residência.

O fenômeno das segundas residências no litoral não é novo. Essa forma de alojamento existe muito antes dos primeiros antecedentes do turismo - que datam do final do século XVII - e se encontra baseado na vilegiatura marítima. López Colás (2003) explica que desde a antiga Roma, durante o verão, os privilegiados fugiam do calor da cidade para o campo, em direção as "aldeias", algumas localizadas a beira-mar, para recreação e jogos. Mas as novas formas geográficas e a geração de fluxo de veraneio em direção ao litoral é o resultado de uma mudança de valores, hábitos e costumes, que paulatinamente transformaram o medo e a aversão ao mar em atração (CORBIN, 1989). Desde o século XVIII o discurso de médicos e higienistas sobre os benefícios da água fria do mar e do ar puro dos ambientes costeiros provocam o deslocamento de doentes as estações balneárias na tentativa de cura de suas enfermidades. Para mais além de questões médicas, Corbin (1989) esclarece que a admiração e o desejo pela beira-mar desperta na nobreza européia o interesse pela moradia temporária nos espaços litorâneos ou diretamente na costa. Seja como for, somente nas últimas décadas o mercado imobiliário reinventou a vilegiatura marítima e tem disponibilizado aos amantes da praia segundas residências articuladas aos serviços turísticos (DANTAS et. al., 2010).

Segundo Camargo (2007), a vilegiatura consiste em um fenômeno social associado a viagens dos citadinos durante o verão para determinadas localidades em recreio, sem outras finalidades. Já Assis (2003) ressalta que a redução da jornada de trabalho, a degradação do meio urbano e o advento do automóvel particular são fatores que motivaram a eclosão do turismo via segunda residência, convertendo o fim de semana, o feriadão e as férias de verão em fatos sócio-culturais característicos da sociedade moderna. Na visão esclarecida de Milton Santos (2001, p. 42) "o automóvel fortalece no seu possuidor a ideia de liberdade do movimento, dando-lhe sentimento de ganhar tempo, de não perder um minuto, neste século de velocidade e pressa". É nesse contexto da sociedade do automóvel que se deve entender o crescimento do modelo fordista do turismo que hoje assume contornos mais flexíveis, complexos e amplos e que possibilita integrar-se com a segunda residência, um 
fenômeno igualmente amplo, complexo, territorial, multidimensional e turístico, que pode inclusive assumir uma função neocolonizadora.

No Brasil, na visão de Becker (1995, p. 10),

\begin{abstract}
o aparecimento do fenômeno da segunda residência dá-se na década de 1950 sob a égide do 'nacional-desenvolvimentismo' que foi responsável pela implantação da indústria automobilística, pela ascensão do rodoviarismo como matriz principal dos transportes e pela emergência de novos estratos sociais médios e urbanos que, aos poucos, começariam a incorporar entre os seus valores sócio-culturais a ideologia do turismo e do lazer (...). O veraneio ou o descanso dos fins de semana se transformou em valor social cuja satisfação levaria o turismo, de um modo muitas vezes predatório e desordenado, a regiões acessíveis a grandes centros urbanos do Centro-Sul, e com atributos valorizados (zonas costeiras e/ou serranas).
\end{abstract}

Embora ocorra também nas férias, o turismo de segunda residência é marcado por viagens curtas, geralmente, nos finais de semana e feriados prolongados. Sendo assim, os destinos turísticos onde se localizam a segunda residência são relativamente próximos à residência principal. De modo geral, pode-se afirmar que o turista tende a procurar locais que ele possa viajar na sexta-feira à noite e retornar no domingo à tarde.

De acordo com Alvarez (1989, p. 76) "centros populosos, bastante urbanizados e industrializados atuam como pontos de origem, e o entorno desses espaços configura-se como áreas de recreio, descanso e lazer". Tulik (2001) sintetiza bem essa questão, estabelecendo a relação centro emissor e centro receptor por meio do tripé tempo-custo-distância. "Esses fatores podem contribuir para a valorização de recursos naturais e culturais mais próximos dos centros emissores, que são preferidos a outros, de qualidade superior, porém mais distantes" (TULIK, 2001, p. 13).

A localização das segundas residências deriva também de outros fatores, como por exemplo, a paisagem, o tipo climático, a acessibilidade, a oferta e a demanda de serviços turísticos, o preço do solo, disponibilidade financeira e a presença e qualidade das vias de acesso (LÓPEZ COLÁS, 2003). De acordo com Assis (2003), a disponibilidade de renda e o tempo livre também são fatores que influenciam na localização da segunda residência, porque quanto mais distante da residência principal maior é o custo e o tempo para ter acesso à residência secundária.

Baseado em evidências no Canadá, Lundgren (1974), um dos estudiosos mais referenciados na literatura sobre padrões de evolução de assentamentos turísticos, produziu um modelo espacial dividido em três fases, 
evidenciando a relação entre o centro urbano emissor e as áreas de concentração das segundas residências.

A primeira fase se inicia com o surgimento de um núcleo de segunda residência em torno do centro urbano, geralmente localizado em espaços com atrativos naturais como praia, rio ou lago. Na segunda fase, as residências se expandem à medida que a área urbana cresce. "Lundgren sugere que a expansão para dentro é de caráter mais urbano, enquanto o impulso para fora ainda retém as características do desenvolvimento característico das casas de veraneio ou de férias" (PEARCE, 2003, p. 331). A terceira fase corresponde ao momento que as segundas residências se tornam a residência principal com a expansão da área metropolitana. Dessa forma, um novo núcleo de segundas residências é formado (Figura 1).

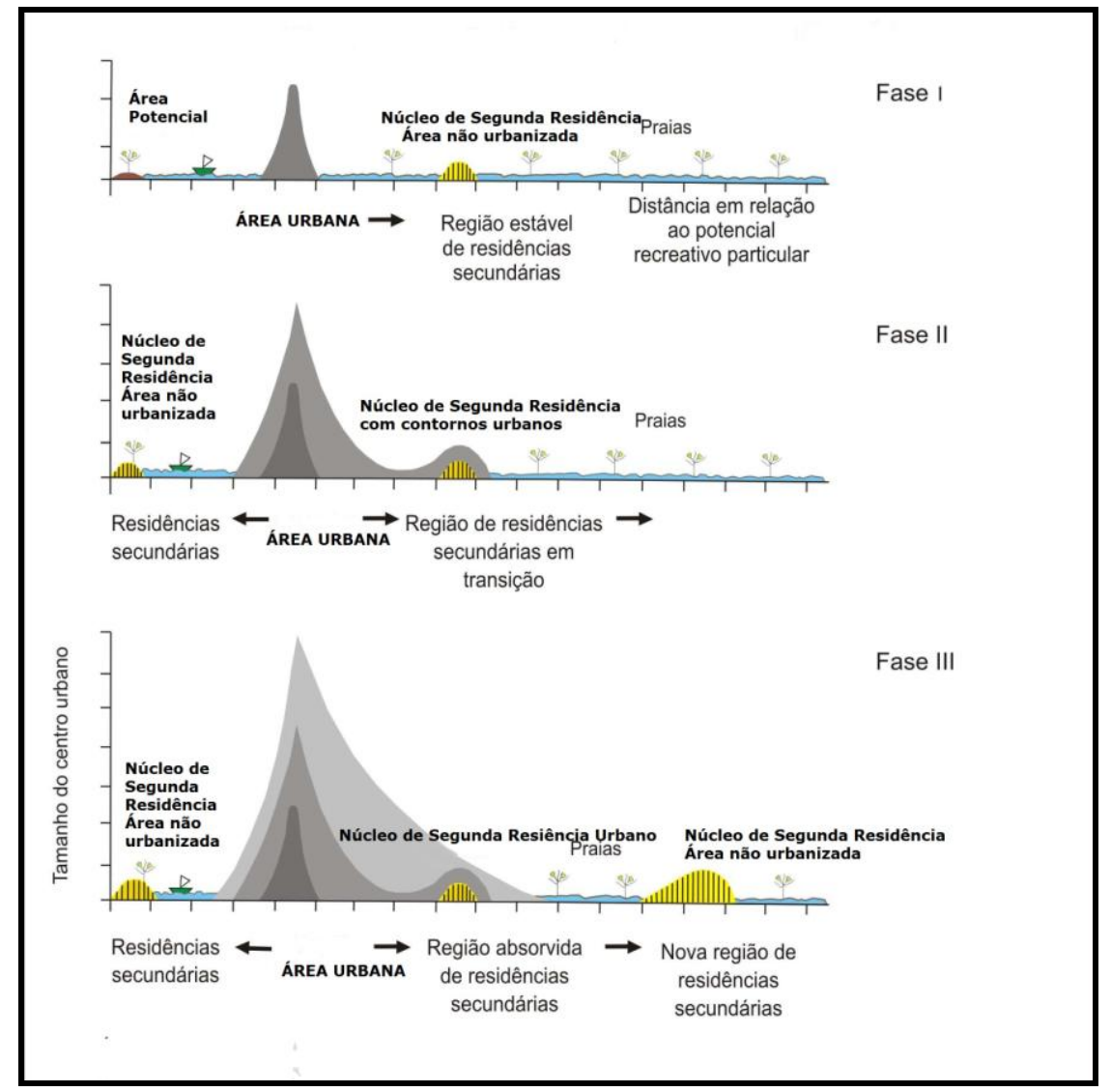

Figura 01. Modelo de Lundgren para Expansão Urbana e para as Regiões de Segundas Residências.

Fonte: PEARCE (2003). Imagem: Carvalho et.al. (2009). Adaptação: Priscila Pereira Santos. 
O litoral brasileiro apresenta significativa concentração de segundas residências. Em 2010, de acordo com os dados da Sinopse Preliminar do Censo Demográfico, os Estados litorâneos apresentavam 88,7 \% do total de domicílios de uso ocasional. $\mathrm{O}$ fenômeno da segunda residência se encontra disseminado em espaços localizados no entorno das capitais estaduais e das grandes aglomerações metropolitanas do litoral brasileiro (MORAES, 2007).

\section{Metodologia}

Para realizar a presente pesquisa foram executados os seguintes procedimentos metodológicos: levantamento e leitura do material bibliográfico; levantamento de dados estatísticos; pesquisa de campo; entrevistas; estabelecimento de uma tipologia de conflitos e de impactos e análise e interpretação dos resultados.

Na primeira etapa do trabalho foram selecionadas obras de geografia do turismo e de segunda residência com foco no território, unidades de conservação de uso sustentável e conflitos socioambientais em zonas costeiras, com especial interesse em autores que abordam a realidade do espaço litorâneo no Nordeste. No caso específico dos conflitos na APA Litoral Sul de Sergipe foram utilizadas dissertações e teses defendidas no Núcleo de Pós-graduação em Geografia da Universidade Federal de Sergipe.

O levantamento de dados estatísticos para identificar o comportamento espacial e temporal da segunda residência foi feito considerando a definição de domicílio de uso ocasional para efeitos do Censo Demográfico de 2000 e 2010. O IBGE (Instituto Brasileiro de Geografia e Estatística) não utiliza a expressão segunda residência, mas define domicílio de uso ocasional como aquele domicílio particular permanente que na data de referência servia ocasionalmente de moradia, ou seja, usado para descanso de fins de semana, férias ou outro fim, mesmo que, na data de referência, seus ocupantes ocasionais estivessem presentes. Os dados foram colhidos por meio da Sinopse dos Censos Demográficos de 2000 e 2010 disponibilizados site do IBGE.

Na etapa seguinte foi realizada a pesquisa de campo para observações in loco, mediante o uso de diário de campo e registros fotográficos entre os meses de novembro e dezembro de 2011 nos finais de semana. A visita aos municípios que fazem parte da APA Litoral Sul (Itaporanga d'Ajuda, Estância, Santa Luzia do Itanhy e Indiaroba) teve como finalidade identificar as implicações socioambientais face aos conflitos territoriais provocados pelo fenômeno da segunda residência. Na oportunidade, foram realizadas entrevistas informais com os moradores permanentes do município de Estância e 
Itaporanga d'Ajuda no intuito de identificar quais seriam as casas utilizadas somente no final de semana para veraneio, qual o tempo de permanência na segunda residência, como acontece à relação entre morador local e o turista de segunda residência em termos de cooperação e conflito. Foi considerado turista de segunda residência o indivíduo que frequenta/possui uma moradia destinada ao lazer e faz uso desta durante o final de semana, o feriado prolongado e às férias.

Entrevistas com roteiro previamente estruturado foram realizadas em novembro de 2011 com dois técnicos da Superintendência de Biodiversidade da Secretaria de Meio Ambiente e Recursos Hídricos de Sergipe (SEMARHSE), responsáveis pelo gerenciamento da APA Litoral Sul, na perspectiva de avaliar os conflitos ambientais e os impactos territoriais resultantes não só do crescimento do número de residências secundárias, mas também do turismo e das intervenções públicas e privadas em termos de estratégias de ordenamento territorial e de construção de loteamentos e empreendimentos imobiliários.

$\mathrm{Na}$ perspectiva de sistematizar o conhecimento sobre os conflitos ambientais e os impactos territoriais produzidos pelo crescimento contínuo e rápido da segunda residência na APA Litoral Sul, foi feito um esforço de síntese por meio de uma tipologia básica de conflitos: conflitos de ocupação territorial, de apropriação dos recursos naturais e conflitos socioambientais. Foi considerada a existência de três sujeitos principais envolvidos nos conflitos (moradores da segunda e da primeira residência e o poder público), os elementos do conflito, o problema central em disputa e os impactos territoriais resultantes.

\section{A APA Litoral Sul de Sergipe e seus problemas socioambientais}

Para preservar e conservar os recursos naturais existentes no território brasileiro foi instituído pela Lei $n^{\circ}$ 9.985/2000 o Sistema Nacional de Unidades de Conservação. O referido sistema estabelece critérios e normas para a criação de unidades territoriais protegidas, as unidades de conservação. A referida Lei faz a seguinte compreensão de Unidade de Conservação (UC): espaço territorial e seus recursos ambientais, incluindo as águas jurisdicionais com características naturais relevantes, legalmente instituídos pelo poder público, com objetivos de conservação e limites definidos, sob regime especial de administração, ao qual se aplicam garantias adequadas de proteção.

A Lei $\mathrm{n}^{\circ} 9.985 / 2000$ no Art. $7^{\circ}$ determina que as unidades de conservação integrantes do SNUC sejam divididas em dois grupos com características bem específicas: a unidade de proteção integral e de uso sustentável. Em outros termos, Unidade de Proteção Integral tem o objetivo 
básico à preservação da natureza e o uso dos seus recursos só é admitido de maneira indireta. A este grupo pertencem as seguintes categorias de UC: Estação Ecológica; Reserva Biológica; Parque Nacional; Monumento Natural; e Refúgio de Vida Silvestre (BRASIL, 2000). Já as Unidades de Uso Sustentável visa compatibilizar a conservação da natureza com o uso direto dos recursos naturais sob o prisma da sustentabilidade, fazem parte desse grupo: Área de Proteção Ambiental; Área de Relevante Interesse Ecológico; Floresta Nacional; Reserva Extrativista; Reserva de Fauna; Reserva de Desenvolvimento Sustentável; e Reserva Particular do Patrimônio Natural (BRASIL, 2000). Aqui nos interessa mais de perto Áreas de Proteção Ambiental (APA) que pertence ao grupo de Unidade de Uso Sustentável.

Em Sergipe, o litoral se configura como um cenário territorial com características urbanas, rurais e espaços naturais, e contém seis unidades de conservação: a Reserva Biológica (REBIO) Santa Isabel e cinco APA's (do Morro do Urubu; Litoral Norte; da Foz do Rio Vaza-Barris; do Rio Sergipe APA Litoral Sul). Localizado no Nordeste do Brasil, o litoral de Sergipe está composto por 23 municípios, dos quais dez são nitidamente costeiros, apresenta cerca de $163 \mathrm{~km}$ de extensão e $5.513,72 \mathrm{~km}^{2}$ de superfície, equivalente a $25,1 \%$ do território sergipano (Figura 02).

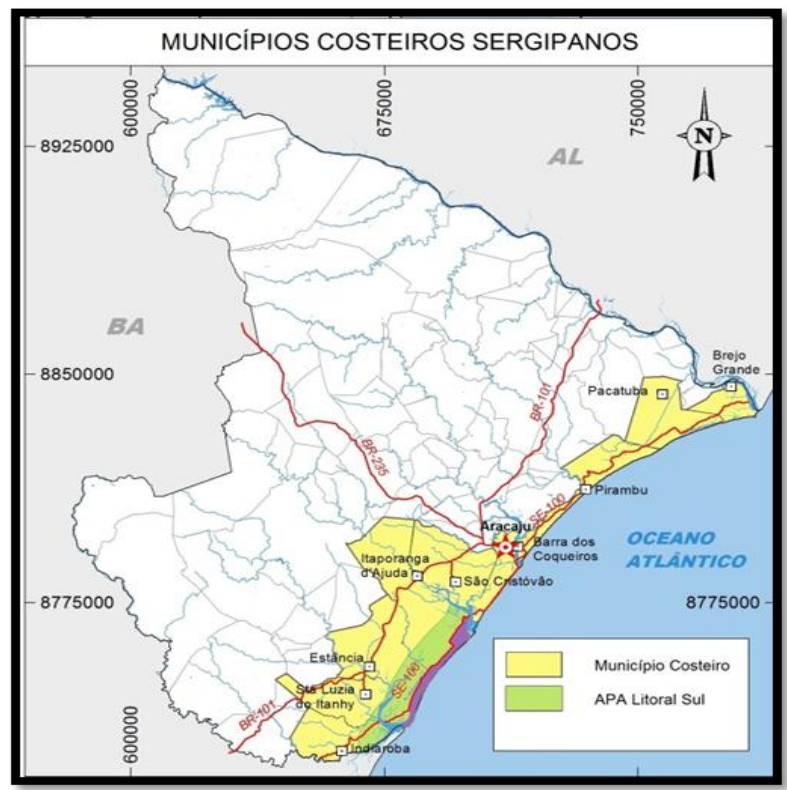

Figura 02: Municípios Litorâneos de Sergipe.

Elaboração: Edson Magalhães. Organização: Os autores. 
O Plano Nacional de Gerenciamento Costeiro (GERCO), instituído pela Lei $N^{o} 7.661 / 88$, tem como objetivo central orientar a utilização racional dos recursos da zona costeira, de forma a contribuir para elevar a qualidade de vida de sua população, e a proteção de seu patrimônio natural, histórico, étnico e cultural. Segundo o GERCO-SE, o litoral sergipano está dividido em três zonas: litoral norte, centro e sul. Para este estudo, o setor sul é posto em evidência no intuito de elucidar os conflitos socioambientais existentes na APA, mas cabe destacar que não inclui o município de São Cristóvão, embora o referido município pertença ao litoral sul pela divisão oficial do GERCO em Sergipe.

O litoral sul dispõe de $2.480,1 \mathrm{~km}^{2}$ de superfície, apresenta acentuada fragilidade ambiental e está composto por cinco municípios: São Cristóvão, Itaporanga d'Ajuda, Estância, Santa Luzia do Itanhy e Indiaroba. Segundo Vilar e Araújo (2010), Sergipe como um todo e o litoral sul em particular, enfrentam problemas ambientais, muitos deles graves e de difícil solução.

$\mathrm{Na}$ perspectiva de ordenamento territorial e com o objetivo de proteger e preservar os ecossistemas litorâneos e costeiros, a biodiversidade e a paisagem natural e cultural desse setor do litoral sergipano, foi instituída a APA Litoral Sul, por meio do Decreto $N^{\circ} 13.468 / 1993$. A APA Litoral Sul possui $55,5 \mathrm{~km}$ de linha de costa, 10 a $12 \mathrm{~km}$ de largura e uma superfície e 542 $\mathrm{km}^{2}$, tendo como limite sul a margem esquerda do Rio Real, na divisa com o Estado da Bahia, ao norte a margem direita do Rio Vaza Barris, ao leste o oceano Atlântico e ao oeste uma linha imaginária entre 10 e $12 \mathrm{~km}$ de distância dos pontos de preamar.

Conforme a Lei $\mathrm{n}^{\circ}$ 9.985/2000, a APA corresponde a um espaço territorial em geral extenso, com certo grau de ocupação humana, dotada de atributos abióticos, bióticos, estéticos ou culturais especialmente importantes para a qualidade de vida e o bem-estar das populações humanas, e tem como objetivos básicos proteger a diversidade biológica, disciplinar o processo de ocupação e assegurar a sustentabilidade do uso dos recursos naturais. Na APA Litoral Sul, observa-se singular patrimônio natural formado por vários ambientes geomorfológicos e biogeográficos, e pelos seguintes geossistemas e geofácies: planície costeira, praias, manguezais, áreas estuarinas, dunas, restingas arbóreas, lagoas, terraços marinhos, cordões litorâneos e manchas preservadas de Mata Atlântica. Apesar dos objetivos da criação da APA Litoral Sul, verificam-se nesse território conflitos socioambientais marcados pelas divergências quanto ao uso e a ocupação do solo.

O turismo e o lazer promovem significativo impacto econômico, ambiental, social, territorial e paisagístico na APA, como por exemplo: a construção irregular de bares e restaurantes, ausência ou inadequação da rede 
de esgotamento sanitário; poluição do mar por resíduos sólidos; destinação inadequada dos resíduos; o desmonte parcial ou total de dunas; desterritorialização dos moradores para áreas mais distantes do seu hábitat em virtude da valorização do solo pela especulação imobiliária, entre outros.

A atividade de carcinicultura também provoca uma série de danos ao meio ambiente local, pois retira a mata ciliar, destrói áreas de mangues e apicum, polui os rios e estuários com os resíduos químicos usados para lavar os viveiros que são despejados sem tratamento adequado no rio, prejudicando a sobrevivência de espécies nativas, como destaque para o caranguejo-uçá. Ademais, a carcinicultura "expulsa" os nativos dos locais onde estão sendo desenvolvida essa atividade para áreas mais interioranas gerando conflitos e impactos.

Outra atividade socioeconômica que gera conflitos socioambientais é o extrativismo da mangaba. A valorização do solo ameaça o desaparecimento do cultivo da mangaba devido a inúmeros fatores, como por exemplo: a especulação imobiliária, a expansão agrícola, a construção de infraestrutura turística, viveiros de camarão e o cultivo de coqueiros, uma vez que a implantação dessas atividades depende do corte das mangabeiras. Segundo Mota et al. (2011, p. 98-99),

\begin{abstract}
as populações de mangabeira situadas nas APA's estaduais (...) encontram-se tão ou mais ameaçadas que os remanescentes situados em áreas de ocupação livre, uma vez que as políticas públicas de desenvolvimento contemplam apenas a construção de infraestruturas turísticas e uso de áreas de preservação permanentes, em vez de conservação e da estrita proibição do corte da vegetação nativa.
\end{abstract}

Na tentativa de normatizar o uso dos recursos territoriais da APA Litoral Sul e diante da obrigatoriedade estabelecida no artigo $2^{\circ}$ da Resolução $\mathrm{n}^{\mathrm{o}} 10$ do CONAMA (Conselho Nacional do Meio Ambiente) foi elaborado pela equipe técnica do GERCO/SE o ZEE (Zona Ecológico-Econômico) do Litoral Sul que inclui, apesar de não fazer parte da APA, o município de São Cristóvão. O ZEE é um instrumento técnico, político, ambiental e econômico de ordenamento territorial, que visa o desenvolvimento socioeconômico planejado de determinado território.

O referido ZEE delimitou 15 (quinze) zonas de usos e restrições de ocupação: zona 1 - Preservação; zona 2 - Alta restrição; zona 3 - Proteção rigorosa; zona 4 - Empreendimentos e Programas Ambientalmente Integrados de Desenvolvimento Turístico; zona 5 - Proteção Especial; zona 6 - Segunda Residência; zona 7 - Agrícola Tradicional e de Ocupação Rarefeita; zona 8 Conservação e Manejo; zona 9 - Turística e de Urbanização Restrita; zona 10 - 
Refúgio da Vida Silvestre; zona 11 - Urbana e Especial I e II; zona 12 Industrial Prioritária I e II; zona 13 - Urbanização - Industrial e de Serviços; zona 14 - Ocupação Irrestrita e Uso Diversificado e zona 15 - Preservação do Patrimônio Histórico e Cultural.

As zonas 2, 4, 6, 8 e 9 tratam diretamente do uso e ocupação do solo da APA pela atividade turística. A zona dois inclui a faixa de praia e estirâncio que apresentam alta restrição de ocupação. A zona quatro engloba setores dos municípios de Indiaroba, Santa Luzia do Itanhy e Estância e permite a criação de empreendimentos de grande porte que apresentem uma política adequada de gerenciamento ambiental. A zona de segunda residência é marcante em localidades costeiras dos municípios de Itaporanga D'Ajuda e Estância, permitida a sua construção com algumas recomendações, é imprescindível a proteção aos recursos hídricos por meio do monitoramento da qualidade da água dos poços tubulares abastecedores das residências; preservação da vegetação arbórea remanescente, além de cuidados e controles específicos quanto aos ecossistemas, principalmente as dunas.

A zona oito, composta de alguns enclaves territoriais nos municípios de Indiaroba e Santa Luzia do Itanhy, apresenta os seguintes segmentos turísticos referenciados enquanto diretrizes de uso e ocupação do solo: Turismo Ecológico e Turismo Rural. A zona nove, por sua vez denominada de Turística e Urbanização Restrita se encontra ancorada nos municípios de Itaporanga D’Ajuda, Santa Luzia do Itanhy, Indiaroba e Estância e se enfatiza o uso dessas localidades pelo Turismo Histórico, Turismo Ecológico e atividades que tenham como prisma de desenvolvimento o respeito ao meio ambiente.

Porém, após a elaboração do ZEE litoral sul, de acordo com a GEOCONSULTORIA (2001), o documento síntese não foi apresentado aos municípios para que fosse diagnosticado e legitimado pela sociedade local. Desse modo, observa-se que a falta da participação popular no ordenamento e planejamento territorial de ambientes costeiros enfraquece a legitimidade dos instrumentos normativos. Nesse sentido, Vilar e Araújo (2010, p. 33) ressaltam que somente com a participação e consulta popular "o ZEE será realmente um instrumento indispensável para pensar a ocupação racional do espaço e a apropriação consciente dos recursos".

\section{Conflitos e Impactos territoriais do Turismo de Segunda Residência na APA Litoral Sul}

Os atrativos territoriais da APA Litoral Sul formam recursos turísticos ocupados basicamente por segundas residências cujos assentamentos tendem a se ampliar, principalmente nas margens das lagoas, nos ambientes de 
praia e nas proximidades das dunas. $\mathrm{O}$ fator de maior expressividade no processo de ocupação territorial do litoral sul é inquestionavelmente a segunda residência e o correspondente desmonte parcial ou total dos campos de dunas e a desconfiguração territorial dos ambientes adjacentes (VILAR e ARAÚJO, 2010).

$\mathrm{Na}$ última década, o crescimento do número de segunda residência nos municípios que abrangem a APA Litoral Sul (Tabela 01) correspondeu a mais de $67,0 \%$, e é atribuído à presença da rodovia SE-100 ao longo de toda faixa litorânea, à construção da ponte interligando Aracaju - capital do Estado a Itaporanga D’Ajuda (Ponte Jornalista Joel Silveira) (Figura 03). É digno mencionar que antes da construção da Ponte o deslocamento de Aracaju até Itaporanga d'Ajuda era realizado por meio de balsas que realizavam a travessia com horários pré-estabelecidos, esta dificuldade de comunicação entre os municípios limitava o crescimento da segunda residência por falta de fluidez territorial que é um requisito básico para a aquisição de uma segunda residência.

Tabela 01: APA Litoral Sul de Sergipe.

Crescimento das residências secundárias. 2000 - 2010.

\begin{tabular}{|l|c|c|c|c|}
\hline $\begin{array}{c}\text { Municípios da APA } \\
\text { Litoral Sul de Sergipe }\end{array}$ & $\begin{array}{c}\text { Residências } \\
\text { Secundárias } \\
\mathbf{2 0 0 0}\end{array}$ & $\begin{array}{c}\text { Residências } \\
\text { Secundárias } \\
\mathbf{2 0 1 0}\end{array}$ & $\begin{array}{c}\text { Crescimento } \\
\text { Absoluto } \\
\mathbf{2 0 0 0 - 2 0 1 0}\end{array}$ & $\begin{array}{c}\text { Crescimento } \\
\text { Percentual\% } \\
\mathbf{2 0 0 0 - 2 0 1 0}\end{array}$ \\
\hline Estância & 1.661 & 2.614 & 953 & 57,37 \\
\hline Itaporanga D'Ajuda & 921 & 1.689 & 768 & 83,38 \\
\hline Indiaroba & 332 & 714 & 382 & 115,06 \\
\hline Santa Luzia do Itanhy & 251 & 285 & 34 & 11,92 \\
\hline Total & $\mathbf{3 . 1 6 5}$ & $\mathbf{5 . 3 0 2}$ & $\mathbf{2 . 1 3 7}$ & $\mathbf{6 7 , 5 1}$ \\
\hline Sergipe & $\mathbf{3 1 . 0 3 4}$ & $\mathbf{4 6 . 9 4 2}$ & $\mathbf{1 5 . 9 0 8}$ & $\mathbf{5 1 , 2 5}$ \\
\hline
\end{tabular}

Fonte: Censo Demográfico do IBGE. 2000 e 2010.

Elaboração: José Wellington Carvalho VILAR e Priscila Pereira SANTOS. 


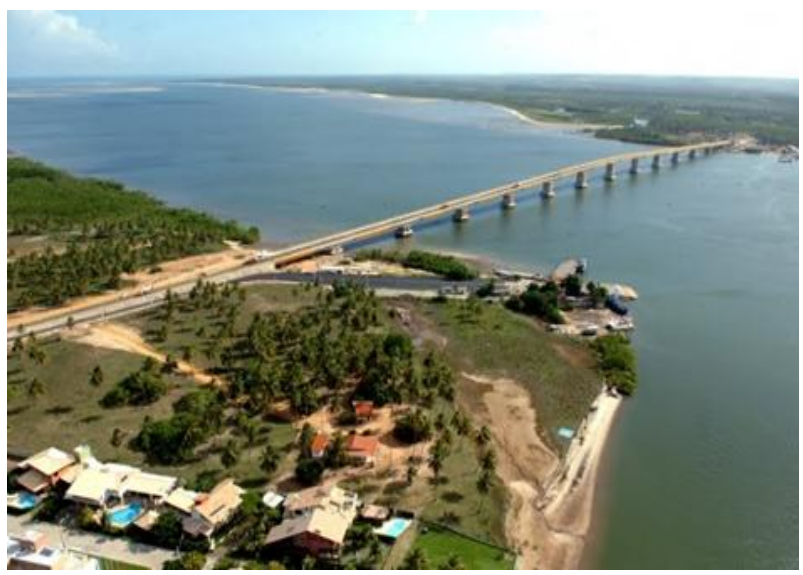

Figura 03: Vista aérea da ponte Jornalista Joel Silveira entre Aracaju e Itaporanga D’Ajuda.

Foto: Marco Vieira, 28/03/2010.

Fonte: http://totinhoaracaju.blogspot.com.br

Além das infraestruturas territoriais já mencionadas, há à construção de infraestruturas complementares, frutos de ações desenvolvidas pelo poder público em sua prática ambígua de ordenamento territorial, principalmente por meio do PRODETUR-SE, do Projeto Orla, do GERCO-SE e mais recentemente das ações do Programa Sergipe Cidades.

É nesse contexto de programas e planos de ordenamento do território, pautada na valorização do litoral e aumento do preço da terra, que se deve entender o crescimento da segunda residência, o aumento de conflitos ambientais e também, a ampliação do número de impactos territoriais. Vale ressaltar que o crescimento relativo dos domicílios de uso ocasional são maiores do que as cifras registradas nas últimas décadas para os domicílios permanentes. Em outros termos, a segunda residência na APA Litoral Sul cresce mais rapidamente do que a primeira residência, e esse é um indicador de valorização do solo e da estratégia territorial de ocupação.

Neste sentido e para efeitos da presente análise, os conflitos estão categorizados em três ordens: conflitos de ocupação territorial, conflitos de apropriação dos recursos naturais e conflitos socioambientais. O quadro 01 é um esforço de síntese para identificar tais conflitos, seus problemas centrais e os impactos mais visíveis no espaço geográfico. 
Quadro 1: Conflitos Ambientais relacionados à segunda residência na APA Litoral Sul de Sergipe.

\begin{tabular}{|c|c|c|c|}
\hline \multicolumn{2}{|r|}{ Conflitos } & \multirow{2}{*}{$\begin{array}{c}\text { Problema } \\
\text { Central }\end{array}$} & \multirow{2}{*}{$\begin{array}{c}\text { Impactos } \\
\text { Territoriais }\end{array}$} \\
\hline 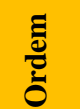 & Elementos & & \\
\hline \multirow{3}{*}{ 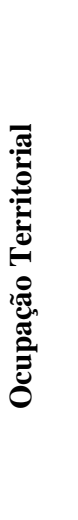 } & $\begin{array}{l}\text { Proprietários da Segunda } \\
\text { Residência versus } \\
\text { Acessibilidade à praia }\end{array}$ & $\begin{array}{l}\text { Restrição do acesso } \\
\text { público à praia }\end{array}$ & $\begin{array}{l}\text { Perda da qualidade visual da } \\
\text { paisagem; diminuição da frequência } \\
\text { à praia; privatização do espaço } \\
\text { público. }\end{array}$ \\
\hline & $\begin{array}{l}\text { Ocupação urbana por } \\
\text { segundas residências } \\
\text { versus Implantação da } \\
\text { APA Litoral Sul }\end{array}$ & $\begin{array}{l}\text { A apropriação e } \\
\text { comercialização de } \\
\text { lotes em APP's }\end{array}$ & $\begin{array}{l}\text { Eliminação parcial ou total da } \\
\text { vegetação original; desmonte total } \\
\text { ou parcial de dunas; redução da } \\
\text { qualidade cênica do lugar. }\end{array}$ \\
\hline & $\begin{array}{l}\text { Expansão de segundas } \\
\text { residências versus } \\
\text { Infraestrutura e serviços } \\
\text { urbanos }\end{array}$ & $\begin{array}{l}\text { Poluição por esgoto } \\
\text { sanitário e resíduos } \\
\text { sólidos }\end{array}$ & $\begin{array}{l}\text { Contaminação do solo e dos corpos } \\
\text { hídricos; ocupação desordenada do } \\
\text { espaço. }\end{array}$ \\
\hline \multirow{2}{*}{ 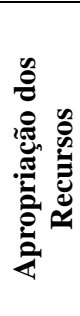 } & $\begin{array}{l}\text { Intensidade da } \\
\text { apropriação dos recursos } \\
\text { versus Capacidade de } \\
\text { carga local }\end{array}$ & $\begin{array}{l}\text { Degradação } \\
\text { Ambiental }\end{array}$ & $\begin{array}{l}\text { Uso indiscriminado dos recursos } \\
\text { naturais. }\end{array}$ \\
\hline & $\begin{array}{l}\text { Territorialidades } \\
\text { "nômades" versus } \\
\text { Territorialidades } \\
\text { permanentes }\end{array}$ & $\begin{array}{l}\text { Percepções variadas } \\
\text { dos recursos } \\
\text { ambientais }\end{array}$ & $\begin{array}{l}\text { Substituição das atividades } \\
\text { econômicas dos moradores locais; } \\
\text { dificuldade de valorização da cultura } \\
\text { local. }\end{array}$ \\
\hline \multirow{2}{*}{ 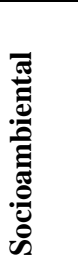 } & $\begin{array}{l}\text { Residência secundária } \\
\text { versus Balneabilidade da } \\
\text { praia }\end{array}$ & $\begin{array}{l}\text { Redução do } \\
\text { potencial turístico }\end{array}$ & $\begin{array}{l}\text { Contaminação do lençol freático; } \\
\text { elevação da incidência de endemias. }\end{array}$ \\
\hline & $\begin{array}{l}\text { Permanência da } \\
\text { população nativa versus } \\
\text { Pressão imobiliária }\end{array}$ & $\begin{array}{l}\text { Migração da } \\
\text { população nativa }\end{array}$ & $\begin{array}{l}\text { Prejuízo à preservação histórica e } \\
\text { cultural da APA Litoral Sul. }\end{array}$ \\
\hline
\end{tabular}

Elaboração: Priscila Pereira Santos; José Wellington Carvalho Vilar. 


\section{- Conflitos de ocupação territorial}

O desencontro entre os objetivos dos veranistas, dos moradores permanentes e o escopo das ações do Estado se manifesta em termos territoriais na dificuldade de acesso aos ambientes de praia, na apropriação de espaços de proteção permanente e na precarização da infraestutura de saneamento e nos serviços urbanos. Nos dois primeiros casos, Vilar e Vieira (2010) destacam como exemplo a realidade dos conflitos de ocupação territorial em função da elitização da Praia do Saco, materializada na segunda residência, seja em forma de construções isoladas, seja nos condomínios fechados, na abertura de loteamentos ou na aglomeração espontânea de casa de veraneio, bem como na apropriação de áreas de preservação permanente, como os campos de dunas e o manguezal. Os impactos territoriais resultantes dessa apropriação manifestamse em termos geográficos na diminuição da freqüência a determinados setores das praias e na eliminação parcial ou total de dunas e da vegetação de mangue.

A construção de segunda residência na linha da costa causa um tipo específico e recorrente de conflito de ordem territorial entre os proprietários das casas de veraneio e os usuários da praia, já que as construções dificultam o livre acesso ao mar, desobedecendo de forma sistemática a Lei $\mathrm{N}^{\mathrm{o}} 7.661 / 88$ que em seu artigo $10^{\circ}$, parágrafo $1^{\circ}$, ressalta a ilegalidade das construções na zona litorânea: "Não será permitida a urbanização ou qualquer forma de utilização do solo na Zona Costeira que impeça ou dificulte o acesso assegurado no caput deste artigo". Uma vez que é assegurado que as praias "são bens públicos de uso comum do povo, sendo assegurado, sempre, livre e franco acesso a elas e ao mar, em qualquer direção e sentido". Os impactos causados por essa apropriação indevida do espaço público correspondem à diminuição da frequência dos nativos nas praias e à diminuição da qualidade cênica da paisagem.

A apropriação, privatização e comercialização de terras nas depressões interdunares, em espaços de pós-praia e áreas de apicum e manguezal para a construção de casas de veraneio na APA Litoral Sul não é compatível com os objetivos de preservação e conservação dos recursos naturais que ocasionou a instituição de uma unidade de uso sustentável dos recursos, pois repercute na transformação da paisagem e na degradação de recursos naturais, uma vez que é necessário eliminar parcial e totalmente a vegetação original e desmontar dunas para construção dessa materialidade geográfica, contribuindo assim para a redução da qualidade visual do lugar (Figuras 04). 

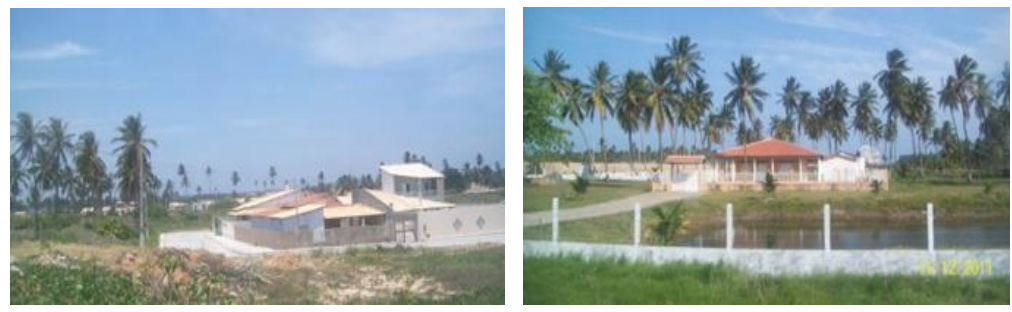

Figura 04: Segundas residências na APA Litoral Sul

Foto: Priscila Pereira SANTOS, 11/12/2011.

\section{- Conflitos de apropriação dos recursos naturais}

A urbanização em curso do território da APA Litoral Sul por casas de veraneio para fins de lazer e turismo traz sérias ameaças aos ecossistemas da zona litorânea, uma vez que a maior parte dos turistas de segunda residência utiliza os recursos naturais de modo insustentável, sem preocupações com os moradores permanentes e tampouco com as gerações futuras e o cenário territorial desejado.

APA Litoral Sul é um território jurídico-político, cultural e econômico no qual diversos grupos com diferentes territorialidades interagem e disputam o domínio dos recursos ambientais para empreender suas atividades. No que tange ao turismo de segunda residência, é evidente o desnível socioeconômico entre esse tipo turista e a comunidade local e tradicional, que pode ser avaliado paisagisticamente em termos do elevado padrão arquitetônico das segundas residências que sinaliza a situação financeira dos seus proprietários, divergente da maioria dos moradores da primeira residência. A escolha dos locais para instalação da segunda residência e sua delimitação territorial não é aleatória, muito pelo contrário, e vai responder a um padrão que combina poder econômico e qualidade paisagística o que amplia os conflitos pela apropriação e uso dos chamados recursos naturais.

$O$ turista de segunda residência apesar de não morar permanentemente cria vínculos territoriais e psicossociais com a APA, e essa percepção dos recursos territoriais pode ser denominada de territorialidade "nômade". Esse modo diferenciado dos turistas de segunda residência de sentir o território influência direta/indiretamente a apropriação dos recursos, tendo em vista a territorialidade dos moradores permanentes. $\mathrm{O}$ aumento do número de segundas residências corresponde mais claramente a uma forma de assentamento urbano e ocasiona a redução de espaços destinados à agricultura e ao extrativismo. Neste contexto, observa-se a substituição de atividades tradicionais voltadas para o extrativismo, que caracterizam ao longo do tempo a 
identidade territorial local, por novas funções socioeconômicas voltadas para a atividade de lazer e construção civil.

A apropriação dos recursos naturais também está associada às dificuldades de organização social e de resgate da identidade territorial dos moradores locais, haja vista que muitos autóctones sentem sua identidade eclipsada pelos turistas de segunda residência, com seus valores urbanos e de classe média. Os conflitos entre territorialidade nômades e territorialidades permanentes se revelam também na percepção diferenciada sobre os recursos, na capacidade de antropização da paisagem e no nível de degradação ambiental. O significado dos recursos para esse par de territorialidades opostas, mas interatuantes se apresenta igualmente de maneira distinta e antagônica, seja como objeto de consumo, seja como forma de sobrevivência.

\section{- Conflitos Socioambientais}

Diante da valorização do território da APA Litoral Sul, principalmente nas áreas próximas ao mar, a pressão imobiliária e a "expulsão" dos nativos geram conflitos de natureza socioambiental associados à desterritorialização da comunidade local, que diante do valor crescente atribuído à terra tende a vender suas propriedades e se deslocar para locais menos valorizados e mais afastados do litoral. É válido registrar que a reterritorialização desses nativos em outros lugares ou em outras atividades locais traz prejuízos à preservação histórica e cultural das comunidades.

Com a expansão urbana, outro sério conflito de natureza socioambiental corresponde à disposição inadequada de resíduos sólidos em lixões e contaminação resultante da ausência de uma rede de esgotamento sanitário. Tais problemas aumentam no período de visitação da APA nos fim de semana ou nas férias pelos turistas das segundas residências e acabam afetando a balneabilidades das praias. Durante a realização do trabalho de campo foi possível observar lixo doméstico, restos de construção civil e esgoto a céu aberto nas praias da Caueira, do Abaís e na Praia do Saco. Nesse sentido, faz-se mister salientar que a poluição por resíduos sólidos pode ocasionar contaminação do lençol freático e elevar a possibilidade de incidência de endemias, trazendo desequilíbrio em termos ambientais e de configuração paisagística, ocasionando, consequentemente, redução do potencial turístico.

Vilar e Vieira (2010) apontam que a construção de segundas residências no litoral sul de Sergipe promove a valorização desse espaço, configurando-se como agente que reforça os problemas socioambientais, pois degrada os atributos naturais e paisagísticos, além de causar conflitos entre a população nativa e os usuários da segunda residência. Tais problemas tornam a 
APA Litoral Sul um campo de conflitos, e os recursos territoriais, objetos de disputa entre os agentes produtores do espaço. A segunda residência convive assim com uma dupla e contraditória situação. Por um lado, a valorização da terra e a especulação imobiliária, por outro, problemas ambientais associados à precarização de infraestrutura de saneamento básico que compromete a qualidade ambiental.

\section{Considerações Finais}

O turismo de segunda residência no litoral sergipano apresenta tendências de crescimento partindo da capital em direção aos municípios do litoral sul. $\mathrm{O}$ aumento da demanda de segundas residências no litoral sergipano acelera os conflitos e intensifica a ocupação desordenada destas áreas. Em locais de grande fragilidade ambiental, como é o caso das praias, apesar dos recursos naturais não se esgotarem com o uso, podem se tornar impróprios como recursos para o lazer, para o ócio e como fatores de atração turística, se não forem utilizados de modo adequado.

A especulação imobiliária, o crescimento das segundas residências, a construção dos eixos estruturantes do espaço e o turismo no litoral sergipano têm provocado significativas modificações paisagísticas, territoriais e sociogeográficas que se manifestam, entre outras coisas, em forma de conflitos ambientais.

A ampliação dos eixos indutores de ocupação e o crescimento do turismo de segunda residência na APA Litoral Sul são acompanhados do aumento de problemas e conflitos ambientais e sociais, como por exemplo, a privatização da praia pela construção de segunda residência na linha da costa, o desmonte de dunas, inadequada disposição final da produção de resíduos sólidos, a pressão da especulação imobiliária, além da segregação socioespacial que consiste na "expulsão" dos nativos dos seus locais de origem para áreas mais afastadas do mar.

Visando orientar as tendências de uso e ocupação no litoral sergipano e os conflitos socioambientais oriundas da proliferação das segundas residências, é evidente a necessidade de um gerenciamento integrado da zona costeira sergipana em busca de um equilíbrio ambiental, econômico, político, social e cultural. Assim, a gestão do desenvolvimento sustentável do turismo de segunda residência deve ser administrada por um sistema onde o poder público, a iniciativa privada e os demais atores envolvidos dividam as responsabilidades e dialoguem de maneira aberta, clara e constante sobre as formas de ordenamento territorial, em outros termos, sobre a forma de futuro territorial que se deseja. 


\section{Referências}

ACSELRAD, H. As práticas espaciais e o campo dos conflitos ambientais. In: ACSELRAD, H. (Org.). Conflitos ambientais no Brasil. Rio de Janeiro: Relume. 2004.

ALVAREZ, J. R. D. Geografía del turismo. Madrid: Síntesis, 1989.

ASSIS, L F de. Turismo de segunda residência: a expressão espacial do fenômeno e as possibilidades de análise geográfica. Revista Território. Rio de Janeiro. Ano VII - $\mathrm{n}^{\circ}$ 11, 12, 13-set./out., 2003.

BACAL, S.. Lazer e o universo dos possíveis. São Paulo: Aleph, 2003.

BECKER, B. K. Levantamento e avaliação da política federal de turismo e seu impacto na região costeira. Brasília: GERCO/PNUMA/MMA, 1995.

BRASIL. Lei $\mathrm{n}^{\circ} 9.985$ de 18 de julho de 2000. Institui o Sistema Nacional de Unidades de Conservação da Natureza - SNUC. Brasília/DF, 2000.

BRASIL. Censo Demográfico. Rio de Janeiro: IBGE, 2000 e 2010.

CAMARGO, H. L. Uma pré-história do turismo no Brasil: recreações aristocráticas e lazeres burgueses (1808-1850). São Paulo: Aleph, 2007.

CARVALHO, S. S. de; SILVA, B. C. N.; MELlO E SILVA, S. de. Globalização, turismo e residências secundárias: o exemplo de Salvador-Bahia e de sua região de influência. Revista Acadêmica. Volume IV - Número 3 - Setembro de 2009.

CORBIN, A. O território do vazio: a praia e o imaginário ocidental. Tradução: Paulo Neves. São Paulo: Companhia das Letras, 1989.

CORRÊA, R. L. Territorialidade e corporação: um exemplo. In: SANTOS, Milton. Território, globalização e fragmentação. São Paulo: HUCITEC, 1996.

DANTAS, E. W C.. Maritimidade nos trópicos. Por uma geografia no litoral. Fortaleza: EdUFC, 2010.

DANTAS, E. W C.; FERREIRA, A.; LIVRAMENTO, M. C. do (Org.). Turismo $e$ imobiliário nas metrópoles. Rio de Janeiro: Letra Capital, 2010.

GEOCONSULTORIA. Zoneamento Ecológico-Econômico do Litoral Sul de Sergipe. Aracaju, 2001.

HAESBAERT, R. $O$ mito da desterritorialização: do "fim dos territórios" à multiterritorialidade. Rio de Janeiro: Bertrand Brasil, 2004.

Geografia Contemporânea. Rio de Janeiro: Bertrand Brasil, 2010.

Regional-Global: dilemas da região e da regionalização na

KRIPPENDORF, J. Sociologia do turismo: para uma nova compreensão do lazer e das viagens. São Paulo: Aleph, 2009. 
LITTLE, P. E. Os conflitos socioambientais: um campo de estudo e de ação política. In: BURSZTYN, M. et.al. (Orgs.). A difícil sustentabilidade. Política energética e conflitos ambientais. Rio de Janeiro: Garamond, 2001.

LÓPEZ COLÁS, J. La residencia secundaria en España: estudio territorial de uso y tenencia. Barcelona, 2003. Tese (Doutorado em Geografia). Universitat de Barcelona.

LUNDGREN, J. O. J. On acess to recreational lands in dynamic metropolitan hinterlands. Tourist Review, n. 29, v. 4, 1974, p. 124-131.

MAZÓN, T.; ALEDO, A. El dilema del turismo residencial: ¿Turismo o desarrollo inmobiliario? In: MAZÓN, T; ALEDO, A. (Orgs.). Turismo residencial y cambio social. Nuevas perspectivas teóricas y empíricas. Alicante: Editorial Aguaclara, 2005.

MORAES, A. C. R.. Contribuições para a gestão da zona costeira do Brasil: elementos para uma geografia do litoral brasileiro. São Paulo: Annablume, 2007.

MOTA, D. M. da et al. A mangabeira, as catadoras e o extrativismo. Belém/Aracaju: EMBRAPA, 2011.

NASCIMENTO, E. P. do N. Os conflitos da sociedade moderna: uma introdução conceitual. In: BURSZTYN, M. et.al. (Orgs.). A difícil sustentabilidade. Política energética e conflitos ambientais. Rio de Janeiro: Garamond, 2001.

OMT. Introducción al turismo. Madrid, 1998.

PEARCE, D. G. Geografia do Turismo. Fluxos e regiões no mercado de viagens. São Paulo: Aleph, 2003.

RAFFESTIN, C. A produção das estruturas territoriais e sua representação. In: SAQUET, M. A.; SPOSITO, E. S. (Org.). Território e territorialidades: teorias, processos e conflitos. São Paulo: Expressão Popular, 2009.

SÁNCHEZ, J-E. Espacio, economía y sociedad. Madri: Siglo Veintiuno Editores, 1991.

SANTOS, M. A natureza do espaço. Técnica e Tempo, Razão e Emoção. São Paulo: EDUSP, 2002.

SANTOS, M.. O dinheiro e o território. Território, Territórios. Programa de PósGraduação em Geografia da Universidade Federal Fluminense/AGB, Niterói, 2002.

SAQUET, M. A. Por uma abordagem territorial. In: SAQUET, M. A.; SPOSITO, E. S. (Org.). Território e territorialidades: teorias, processos e conflitos. São Paulo: Expressão Popular, 2009.

SOUZA, M. L. de. "Território" da divergência (e da confusão): em torno das imprecisas fronteiras de um conceito fundamental. In: SAQUET, M. A.; SPOSITO, E. S. (Org.). Território e territorialidades: teorias, processos e conflitos. São Paulo: Expressão Popular, 2009. 
SOUZA, M. L. de. O território: sobre espaço e poder, autonomia e desenvolvimento. In: CASTRO, I. E. de et. al. (Orgs.). Geografia: conceitos e temas. Rio de Janeiro: Bertrand Brasil, 1995.

TULIK, O. Turismo e meio de hospedagem: casas de temporada. São Paulo: Roca, 2001.

VIEIRA, L. V. L. Conflitos socioambientais e territorialidades no litoral norte de Sergipe. Tese (Doutorado em Geografia). São Cristóvão: UFS, 2010.

VILAR, J. W. C; ARAÚJO, H. M. Iniciativas de ordenamento territorial no litoral sul de Sergipe. In: VILAR, J. W. C; ARAÚJO, H. M. (Orgs.). Território, Meio Ambiente e Turismo no litoral sergipano. São Cristóvão: EDUFS, 2010.

VILAR, J. W. C.; VIEIRA, L. V. L. A dinâmica sócio-demográfica e os conflitos territoriais no litoral sul de Sergipe. In: VILAR, J. W. C.; ARAÚJO, H. M. (Orgs.) Território, Meio Ambiente e Turismo no litoral sergipano. São Cristóvão: EDUFS, 2010.

\section{Priscila Pereira Santos}

Tecnóloga em Gestão de Turismo.

Instituto Federal de Educação, Ciência e Tecnologia de Sergipe.

E-mail: p.p.s2902@gmail.com

José Wellington Carvalho Vilar

Doutor em Ordenamento Territorial pela Universidad de Granada - Espanha.

Professor do Curso de Tecnologia em Saneamento Ambiental e Gestão de

Turismo - Instituto Federal de Educação, Ciência e Tecnologia de Sergipe.

Professor do Núcleo de Pós-Graduação em Geografia

Universidade Federal de Sergipe (UFS)

E-mail: wvilar@yahoo.com.br

Recebido para publicação em maio de 2012

Aprovado para publicação em março de 2013 